\title{
Synthesis of $\mathrm{LiMn}_{0.9} \mathrm{Ni}_{0.1} \mathrm{PO}_{4} / \mathrm{C}$ as New Cathode Material for Lithium Battery
}

\author{
Bambang Prihandoko ${ }^{a^{*}}$ and Achmad Subhan ${ }^{\mathrm{a}}$
}

a Research Centre for Physics - LIPI, PUSPIPTEK Tangsel Indonesia

\begin{abstract}
Lithium ion battery has high energy density and good application for electrical vehicle and power grid under combination with photovoltaic. Carbon coated lithium manganese phosphate is the new cathode active material. In this experiment $\mathrm{LiMn}_{0.9} \mathrm{Ni}_{0.1} \mathrm{PO}_{4} \backslash \mathrm{C}$ was carried out with stoichiometric composition of technical raw materials, $\mathrm{MnO}_{2}$ from China, Ni from Merck, $\mathrm{H}_{3} \mathrm{PO}_{4}$ and LiOH. $\mathrm{H}_{2} \mathrm{O}$ from Germany. After calcinations process at $700^{\circ} \mathrm{C}$ in 2 hours by powder metallurgy method, sintering was done during of 2 hours. Before sintering process calcinations powder was milled and mixed with tapioca powder under comparison between tapioca and active material 1:3 in 72 hours. The sintered powders was analyzed the characteristic of crystal structure, SEM, conductivity, cyclic voltammeter and charge - discharge. The sintered powder has black color under coated carbon from tapioca. The crystal structure of LiMn $0.9 \mathrm{Ni}_{0.1} \mathrm{PO}_{4} \backslash \mathrm{C}$ has the same olivine structure of $\mathrm{LiMnPO}_{4} \backslash \mathrm{C}$. Networking structure of phosphate in $\mathrm{LiMn}_{0.9} \mathrm{Ni}_{0.1} \mathrm{PO}_{4} \backslash \mathrm{C}$ was formed in the FTIR analysis. Conductivity of active material was $7.96 \mathrm{x} 10^{-6} \mathrm{~S} / \mathrm{cm}$. Workings voltage of $\mathrm{LiMn}_{0.9} \mathrm{Ni}_{0.1} \mathrm{PO}_{4} \backslash \mathrm{C}$ was 4.2 volt with capacity of round $40 \mathrm{mAh} / \mathrm{g}$.
\end{abstract}

Keywords: cathode, $\mathrm{LiMnPO}_{4}$, lithium battery, powder metallurgy, tapioca

\section{Introduction}

Lithium ion battery has high energy density and good application for electrical vehicle and power grid under combination with photovoltaic. Lithium ion batteries have been widely applied as power sources for electronic devices such as cameras, mobile phones, computers and other related devices. Recently, lithium ion batteries have also attracted attention as electric sources for electric and hybrid electric vehicles (EVs and HEVs) (Bruno et. al.2010). In fact, the development of lithium ion batteries with high power and high energy density is the key to their successful application in EVs and HEVs (Duncan et. al.2011).

Lithium transition-metal (ortho) phosphates have recently attracted attention as potential Li-ion battery cathode materials due to their lower toxicity, lower cost and better chemical and thermal stability, when compared to the currently used $\mathrm{LiCoO}_{2}$. The threedimensional framework of an olivine is stabilized by the strong covalent bonds between oxygen ions and the $\mathrm{P}^{5+}$ resulting in $\mathrm{PO}_{4}{ }^{3-}$ tetrahedral polyanions (Duncan et. al.2011; Bakenov et. al.,2011). As a consequence, olivine lithium metal phosphate materials do not undergo a structural re-arrangement during lithiation and de- lithiation. This means that they do not experience the capacity fade during cycling suffered by lithium transition metal oxides such as $\mathrm{LiCoO}_{2}, \mathrm{LiNiO}_{2}, \mathrm{LiMnO}_{2}$ and $\mathrm{LiMn}_{2} \mathrm{O}_{4}$. This is attributed to structural rearrangements caused during lithiation and delithiation (Bruno et. al.2010).

$\mathrm{LiMnPO}_{4} / \mathrm{C}$ has a higher working voltage (4volt) than $\mathrm{LiFePO}_{4} / \mathrm{C}$ (3.5volt). Lithium manganese phosphate has a redox potential of $4.1 \mathrm{~V}$ versus $\mathrm{Li}^{+} / \mathrm{Li}$ (Bruno et. al.2010; Seung-Min et.al, 2011). which is considered to be the maximum limit accessible to most liquid electrolytes. Unfortunately, $\mathrm{LiMnPO}_{4}$ has a low intrinsic electronic and ionic conductivity and hence a poor discharge rate capability.

$\mathrm{LiNiPO}_{4} / \mathrm{C}$ has workings voltage of 5.1 Volt and diffusion coeffisient of $10^{-5} \mathrm{~cm}^{2} / \mathrm{s}$ (Seung-Min et.al, 2011). By this high characterisation, at this experiment, nickel would be substituted of manganese in $\mathrm{LiMnPO}_{4} / \mathrm{C}$ to increase workings voltage and conductivity.

\footnotetext{
* Corresponding Author:

Email: prihandoko1@yahoo.com
} 


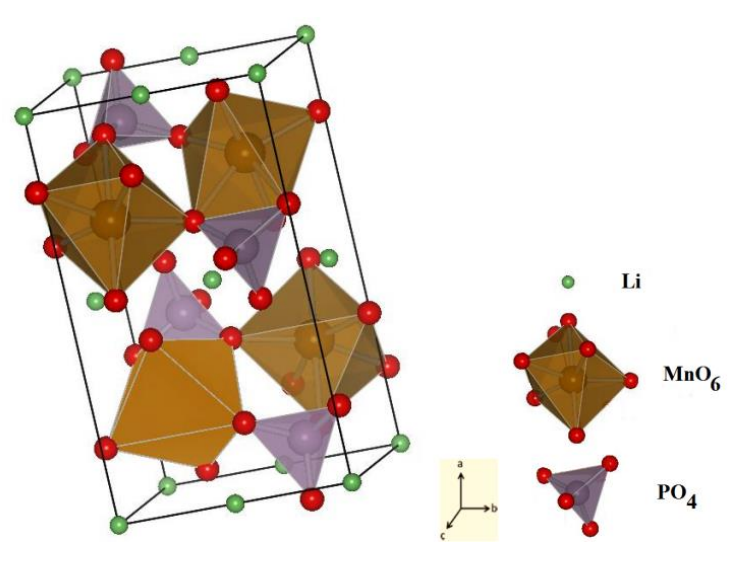

Fig.1. Olivine crystal structure of $\mathrm{LiMnPO}_{4}$.

\section{Material and Method}

In this experiment $\mathrm{LiMn}_{0.9} \mathrm{Ni}_{0.1} \mathrm{PO}_{4} \backslash \mathrm{C}$ was carried out with stoichiometric composition of technical raw materials, $\mathrm{MnO}_{2}$ from China, $\mathrm{Ni}$ from Merck, $\mathrm{H}_{3} \mathrm{PO}_{4}$ and LiOH. $\mathrm{H}_{2} \mathrm{O}$ from Germany that synthesis of $\mathrm{LiMn}_{0.9} \mathrm{Ni}_{0.1} \mathrm{PO}_{4} \backslash \mathrm{C}$ was done by powder metallurgy method. After calcinations process at $700^{\circ} \mathrm{C}$ in 2 hours, calcinations powder was mixed and milled with tapioca powder under comparison between tapioca and active material $1: 3$ in 72 hours. Sintering was done during 2 hours.

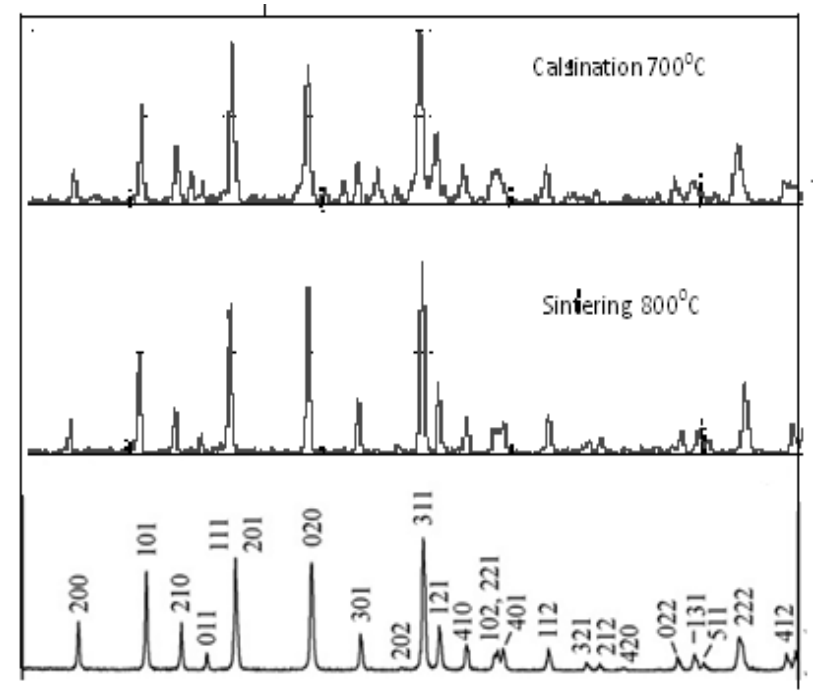

$2 \Theta$ degree

Fig.2. XRD pattern of $\mathrm{LiMn}_{0.9} \mathrm{Ni}_{0.1} \mathrm{PO}_{4} \backslash \mathrm{C}$
The sintered powders was analyzed the characteristic of crystal structure, SEM, conductivity, cyclic voltammeter (CV) and charge - discharge (CD). $\mathrm{LiMn}_{0.9} \mathrm{Ni}_{0.1} \mathrm{PO}_{4} \backslash \mathrm{C}$ powder was mixed with $5 \%$ carbon black from tapioca powder as filler of composite cathode material. The used binder was PVdF with solution dimethyl acetamide (DMAC) to make composite matrix. A slurry of the composite was coating at $\mathrm{Al}$ foil. The result of cathode composite at $\mathrm{Al}$ foil was used as sample for conductivity test.

Conductivity test used method of Electrochemical Impedance Spectrometry (EIS) with HIOKI from Japan. Cyclic Voltammeter (CV) and Charge - Discharge (CD) test of $\mathrm{LiMn}_{0.9} \mathrm{Ni}_{0.1} \mathrm{PO}_{4} \backslash \mathrm{C}$ used half cell sample. The cathode composite was attached on stainless steel screen. Anode material was lithium metal. CV and CD test used equipment of automatic battery cycler from WBCS300 from South Korea.

\section{Results and Discussion}

By XRD analysis the crystal structure of $\mathrm{LiMn}_{0.9} \mathrm{Ni}_{0.1} \mathrm{PO}_{4} \backslash \mathrm{C}$ was the same with $\mathrm{LiMnPO}_{4} / \mathrm{C}$ (Fig.1). After calcination at a temperature of $700^{\circ} \mathrm{C}$ results were still not perfect reacting, so there is impurity seen in the XRD pattern. After sintering at $800^{\circ} \mathrm{C}$ temperature XRD pattern was shown similarities with the results of reference (Koleva et. al., 2010). Shifted peak were happening, but impurity almost nothing.

Carbon as a coated result was not appear on the pattern, because carbon has an amorphous phase. Coated carbon visible in the Scanning Electron Microscope (SEM) and Energy-dispersive X-ray (EDX) analysis, see Fig.3. Coated carbon had wave-shaped in surface samples. Carbon levels in the EDX analysis was 2.7\%. Impurity apparent $\mathrm{N}$ and $\mathrm{Si}$ is about $5 \%$. 

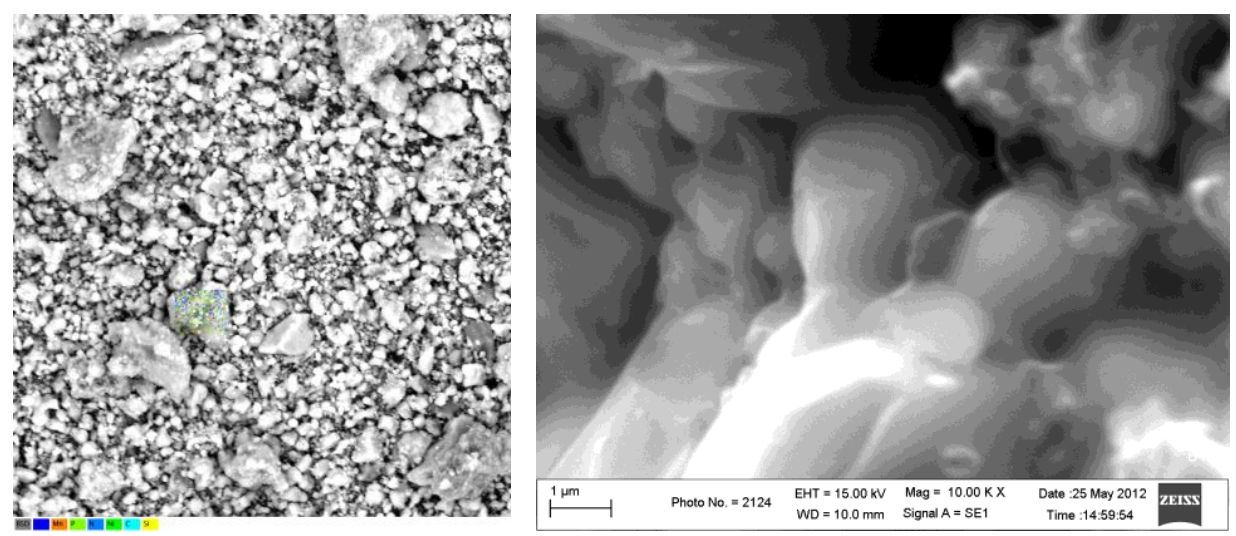

\begin{tabular}{|c|c|c|}
\hline & Weight percentage & Certainty \\
\hline 0 & $61.6 \%$ & $97.1 \%$ \\
\hline $\mathrm{Mn}$ & $12.3 \%$ & $96.0 \%$ \\
\hline$P$ & $10.7 \%$ & $97.0 \%$ \\
\hline $\mathrm{N}$ & $8.0 \%$ & $92.9 \%$ \\
\hline $\mathrm{Ni}$ & $3.6 \%$ & $86.3 \%$ \\
\hline C & $2.7 \%$ & $92.9 \%$ \\
\hline Si & $1.1 \%$ & $87.5 \%$ \\
\hline
\end{tabular}

Fig.3. SEM photos and EDX analysis of $\mathrm{LiMn}_{0.9} \mathrm{Ni}_{0.1} \mathrm{PO}_{4} \backslash \mathrm{C}$

The formation of olivine-type $\mathrm{LiMnPO}_{4} \backslash \mathrm{C}$ is also supported by IR spectroscopy (Fig. 4). The sample annealed at temperature $800^{\circ} \mathrm{C}$ exhibit an IR spectrum typical of well crystallized olivine-type $\mathrm{LiMnPO}_{4}$ (Koleva et. al., 2010). The four bands at 955, 1038, 1093 and

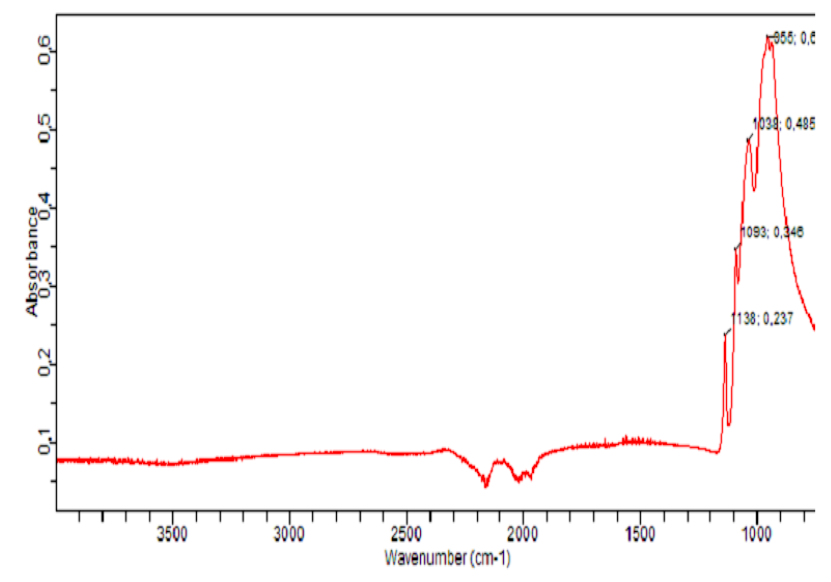

Fig.4. IR spectroscopy analysis of $\mathrm{LiMn}_{0 .} \mathrm{Ni}_{0.1} \mathrm{PO}_{4} \backslash \mathrm{C}$
$1138 \mathrm{~cm}^{-1}$ defined as the asymmetric stretching PO vibrations of $\mathrm{PO}_{4}{ }^{3-}$. There four bands like as the four bands 991, 1055, 1094 and $1138 \mathrm{~cm}^{-1}$ from analysis result of reference (Koleva et. al., 2010).

The first tree wave numbers decreased from the wave numbers of reference. The vibrations of $\mathrm{PO}_{4}{ }^{3-}$ of sample gave that sample had a formation of frame networking $\mathrm{PO}_{4}{ }^{3-}$ as olivine crystal structure.

The conductivity of $\mathrm{LiMn}_{0.9} \mathrm{Ni}_{0.1} \mathrm{PO}_{4} \backslash \mathrm{C}$ from EIS analysis gave in Fig. 5 where impedance is function of frequency. The impedance line was not strike line and value was $3.65 \times 10^{4} \mathrm{Ohm}$. The conductivity of $\mathrm{LiMn}_{0.9} \mathrm{Ni}_{0.1} \mathrm{PO}_{4} \backslash \mathrm{C}$ was $7.96 \times 10^{-6} \mathrm{~S} / \mathrm{cm}$ that was more higher than $\mathrm{LiMnPO}_{4}$ without coated carbon about $3 \mathrm{x}$ $10^{-9} \mathrm{~S} / \mathrm{cm}[6]$. 


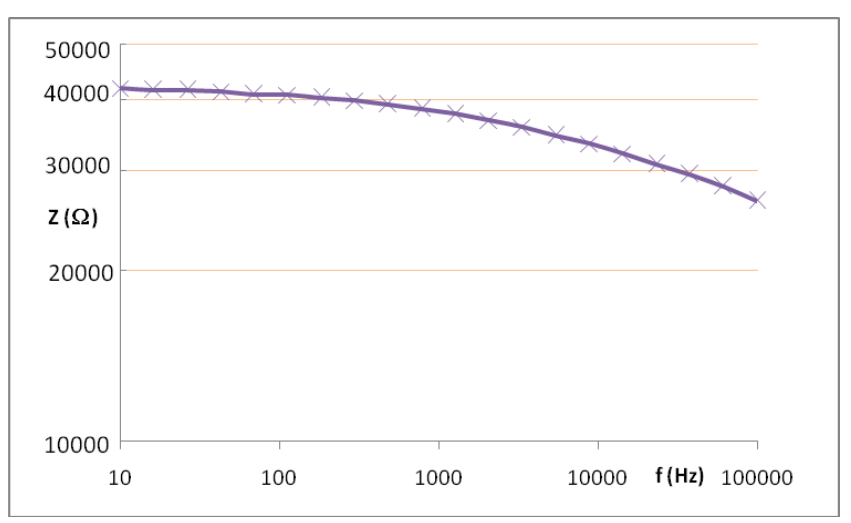

Fig. 5. Impedance graphic of $\mathrm{LiMn}_{0.9} \mathrm{Ni}_{0.1} \mathrm{PO}_{4} \backslash \mathrm{C}$

The electrochemical test for a active material of lithium battery is cyclic voltammeter that gave about oxidation and reduction reaction of active material. Fig. 6 shows a result of $\mathrm{LiMn}_{0.9} \mathrm{Ni}_{0.1} \mathrm{PO}_{4} \backslash \mathrm{C}$ test with rate $20 \mu \mathrm{V} / \mathrm{s}$. Oxidation reaction was not clearly apparent in the graphics, but reduction reaction was clear. The graphic was not perfect cycles of oxidation and reduction reaction of active material.

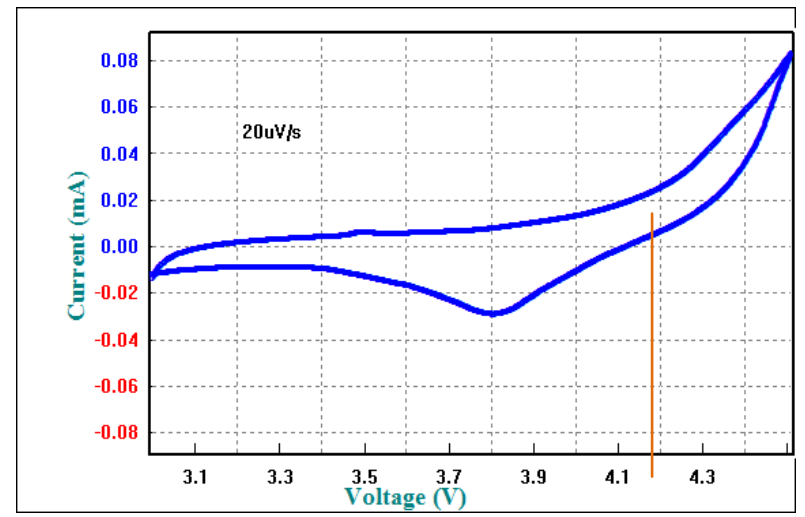

Fig. 6. Cyclic voltammeter of $\mathrm{LiMn}_{0.9} \mathrm{Ni}_{0.1} \mathrm{PO}_{4} \backslash \mathrm{C}$

From cyclic voltammeter analysis $\mathrm{LiMn}_{0.9} \mathrm{Ni}_{0.1} \mathrm{PO}_{4} \backslash \mathrm{C}$ had workings voltage of round 4.2 volt and capacity of round $40 \mathrm{mAh} / \mathrm{g}$.

The result of charge - discharge test was shown in Fig. 7 in the range 3.5 to 4.5 volt. Charge - discharge was done a good cycles by four cycles. After 4 cycles charge discharge worked not good. Working voltage was decreasing and current of charge and discharge was stabile. If we shown more detail, discharge line worked not flat and more decline. That gave a polarization line of discharge process. The active material of $\mathrm{LiMn}_{0.9} \mathrm{Ni}_{0.1} \mathrm{PO}_{4} \backslash \mathrm{C}$ had a drop process during discharge. This test of charge - discharge must be done by more samples.
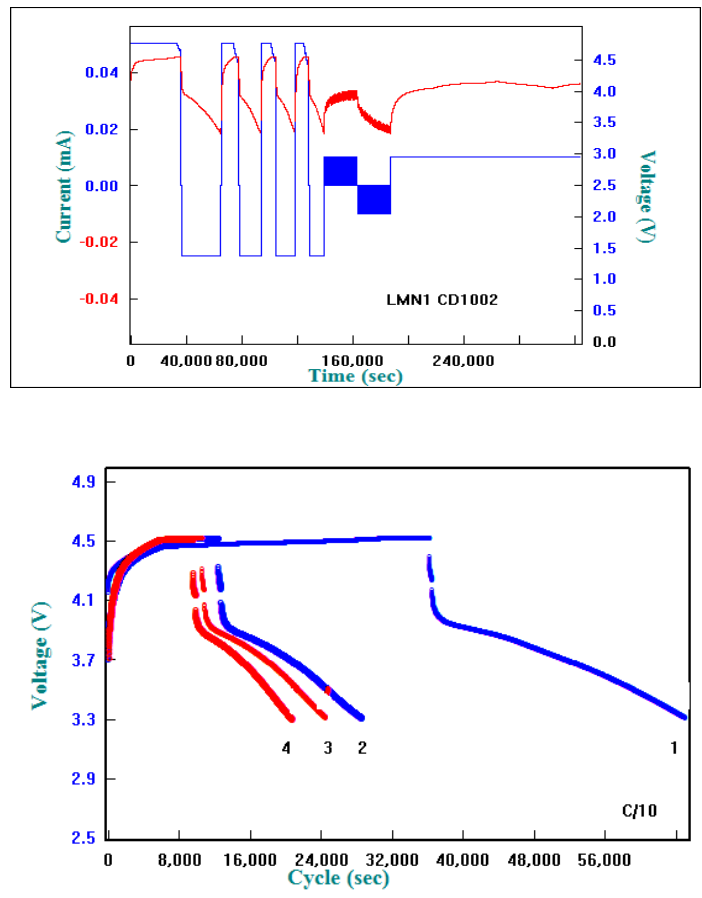

Fig. 7. Charge - discharge graphic of $\mathrm{LiMn}_{0.9} \mathrm{Ni}_{0.1} \mathrm{PO}_{4} \backslash \mathrm{C}$

\section{Conclusion}

$\mathrm{LiMn}_{0.9} \mathrm{Ni}_{0.1} \mathrm{PO}_{4} \backslash \mathrm{C}$ has characteristic for cathode active material of lithium battery, like as:

- olivine crystal structure

- conductivity of $7.96 \times 10^{-6} \mathrm{~S} / \mathrm{cm}$

- working voltage of 4.2 volt.

- capacity round $40 \mathrm{mAh} / \mathrm{g}$

- charge discharge cycles

The active material of $\mathrm{LiMn}_{0.9} \mathrm{Ni}_{0.1} \mathrm{PO}_{4} \backslash \mathrm{C}$ must be more improvement to make a good cathode material for lithium battery in the next experiment.

\section{Acknowledgment}

Authors are grateful to the financial support from Indonesian Institute of Science (LIPI) by competitive project. 


\section{References}

Bruno Scrosati, Jürgen Garche, (2010) Review Lithium batteries: Status, prospects and future, J. Power Sources 195 2419-2430.

Duncan Kushnir*, Björn A. Sandén, (2011) Multi-level energy analysis of emerging technologies: a case study in new materials for lithium ion batteries, Journal of Cleaner Production, 19 1405-1416

Seung-Min Oh, Hun-Gi Jung, Chong Seung Yoon, Seung-Taek Myung, Zonghai Chen, Khalil Amine, Yang-Kook Sun, (2011) Enhanced electrochemical performance of carbon- $\mathrm{LiMn}_{1-x} \mathrm{Fe}_{\mathrm{x}} \mathrm{PO}$ nanocomposite cathode for lithium-ion batteries, Journal of Power Sources 196 6924-6928
V. Koleva, R. Stoyanova, E. Zhecheva, Nano-crystalline LiMnPO ${ }^{4}$ prepared by a new phosphate-formate precursor method, Materials Chemistry and Physics121 (2010) 370-377.

V. Ramar, K. Saravanan, S.R. Gajjela, S. Hariharan, P. Balaya, (2013) The effect of synthesis parameters on the lithium storageperformance of $\mathrm{LiMnPO}_{4} / \mathrm{C}$, Electrochimica Acta 105 496505

Zhumabay Bakenov, Izumi Taniguchi, (2011) LiMnP04 Olivine as a Cathode for Lithium Batteries, The Open Materials Science Journal, 5 , (Suppl

$1:$ M4) $222-22$ 